\title{
LOGICAL-INFORMATION SUBSYSTEM OF THE EXPERT SYSTEM FOR THE DESIGN OF MULTI-ASSORTMENT LOW-TONNAGE PAINT AND VARNISH INDUSTRIES
}

\author{
1'Veniamin BOLDYREV, ${ }^{2,3}$ Vladimir MEN'SHIKOV, ${ }^{2}$ Anastasiya SAVINA, ${ }^{1,2}$ Nikita BOGATOV, \\ ${ }^{3}$ Yana Seina KUZNETSOV, ${ }^{2}$ Aleksandr ZOTKIN, ${ }^{1}$ Anastasiya RAZVODOVA \\ ${ }^{1}$ Bauman Moscow State Technical University, Moscow, Russia, boldyrev.v.s@bmstu.ru \\ ${ }^{2}$ D. Mendeleev State Technical University, Moscow, Russia \\ ${ }^{3}$ Scientific Production Association «Lakokraspokrytiye», Khotkovo, Moscow region, Russia, mail@npolkp.ru
}

https://doi.org/10.37904/metal.2021.4178

\begin{abstract}
The article describes an integrated expert system that describes the models of actions of technologists and designers, helping to efficiently work in modern production conditions and meeting their requirements. The proposed system contains algorithms that allow you to optimize complex chemical-technological processes, characterized by an arbitrary discipline of production. The structure of the expert system and its functions are described.
\end{abstract}

Keywords: Expert system, chemical-technological process, paints and varnishes, algorithm

\section{INTRODUCTION}

The production of paints and varnishes in the current economic situation is characterized by frequent structural modifications of the product range, which adequately reflect the state of the consumer market [1-2], to which production must quickly adapt, while spending a minimum amount of resources. Manufacturing that meets modern requirements is designed and created under conditions of incomplete, poorly formalized information, and therefore it is advisable to design it using the methods of an integrated expert system (ES) specially developed for this purpose, the structure and functions of which are below.

The developed ES, along with traditional means that simulate the actions of technologists and designers, contains effective algorithms for the optimization of chemical-technological systems (CTS) with a complex hardware structure and an arbitrary discipline of production.

The expert system consists of information-logical and calculation subsystems. The function of the informationlogical subsystem of the ES consists in the choice by the designer in the dialogue mode of the type of hardware composition, the structure of technological systems, types of technological equipment adequate to the range of products, an optimizing mathematical model, as well as effective algorithms for structural and parametric optimization [3-5]. The ES calculation subsystem optimizes the hardware structure and the hardware composition of the chemical-technological system. In order to select the set of admissible objects in each of their classes, admissible combinations of values of information signs are determined.

The search for the optimal route for solving the problem of optimizing the chemical-technological system for the production of paints and varnishes is carried out in the form of a multipurpose procedure. First, the optimal types of technological equipment are selected for each stage of the technological process for obtaining target or intermediate products [4-7]. Structural and functional elements act as information signs of standard technological equipment. The conjunction of the values of information signs determines the structural type of the apparatus. For non-standard technological devices, the values of some information features cannot be 
practically realized, therefore, the design of non-standard equipment is determined by the methods of morphological analysis.

\section{ALGORITHM}

To optimize the route, admissible objects are pre-selected; in this case, objects characterized by the combined values of information signs are considered acceptable. The determination of the admissibility of optimization objects was carried out by the method of morphological analysis in the form of a morphological box, which is applied to non-standard technological equipment, structural types of technological systems, classes of their optimizing structural-functional models and to optimization algorithms. For this purpose, for each class of objects under study, a space of information signs is formed:

$$
F^{i}(i=\overline{1, n})
$$

which describe the objects under study with sufficient completeness. Each feature is assigned a set of values $A_{p}^{i}\left(i=1, J_{i}\right)$. A list of lists is constructed by enumerating various combinations of features $A_{j}^{1}, A_{j 2}^{2}, \ldots A_{j n}^{n}$, the total number of which:

$$
N=\prod_{i=1}^{n} J_{i}
$$

The process of morphological analysis is formalized in the form of a matrix of binary relations $B^{i, k}(i, k=1, n)$, elements of which $b^{i, k}, q$ take values:

$$
b_{p, q}^{i, k}=\left\{\begin{array}{l}
0 \\
1
\end{array}\right.
$$

where:

0 if the values $A_{p}^{i}$ and $A_{q}^{k}$ are inconsistent

1 if the values $A_{p}^{i}$ and $A_{q}^{k}$ are consistent

A necessary condition for the admissibility of the optimization option is the fulfillment of the equality:

$$
\prod_{i=1}^{n-1}\left(\prod_{k=i+1}^{n} b_{J_{1}, J_{k}}^{i, k}\right)=1
$$

corresponding to the pairwise compatibility of all characteristic values included in the variant.

Then, using the method of searching for non-dominated alternatives, the optimal one is selected from the admissible options for the hardware design of each stage of the technological process. The search for alternative types of devices and the hardware structure of $X$ technological systems, as well as classes of structural-functional models and optimization algorithms, is formally a task of multi-criteria optimization with fuzzy information.

With known membership functions of fuzzy criteria for a set of objects $X$, a system of fuzzy binary relations of non-strict $R$ and strict $P$ preference relations is determined $\langle R, P\rangle$. Under the assumption that it is advisable to select an object by the totality $C_{k}$ - criteria $(k=1, m)$, even for small values of some of them, the choice is carried out according to a compromise model, in accordance with which the membership functions of a strict 
$\mu_{R}(x, y)$, non-strict $\mu_{P}(x, y)$ preference of object $X$ over object $Y$ and fuzzy choice $\mu_{P}(x)$, are sequentially calculated using the following formulas:

$$
\begin{aligned}
& \mu_{R}(x, y)=1-\sum \alpha_{k}\left[\mu_{k}(y) \theta \mu_{k}(x)\right], \quad x, y \in X \\
& \mu_{k}(y) \theta \mu_{k}(x)=\max \left[0, \mu_{k}(y)-\mu_{k}(x)\right] \\
& \mu_{P}=\mu_{k}(y) \theta \mu_{k}(x), x, y \in X \\
& \mu_{D}(x)=\frac{1}{N-1}\left\{\sum_{y \in x, x \neq x} \mu_{P}(x, y) \theta \sum_{y \in x, x \neq x} \mu_{P}(x, y)\right\}, \quad x \in X,
\end{aligned}
$$

where:

$\theta$ is the symbol of limited subtraction

$\alpha_{k}$ is the normalized weighting coefficient of the $k$-th criterion $C_{k}$

$\mu_{R}(x, y)$ is the membership function of strict preference of object $X$ to object $Y$

$\mu_{P}(x, y)$ is the membership function of non-strict preference of object $X$ to object $Y$

$\mu_{P}(x)$ is a fuzzy choice function

The weight coefficients $\alpha_{k}$ of the criteria $C_{k}$ are obtained by the corresponding processing of the matrix A, formed in accordance with the Saaty scale. Moreover, a necessary and sufficient condition for the existence of $\alpha_{i}$ formed in accordance with the Saaty scale. Moreover, a necessary and sufficient condition for the existence of:

$a_{i, j}=\frac{\alpha_{i}}{\alpha_{j}}, \forall i, j$

Where $\alpha_{i, j}$ is an element of the matrix $A$.

Since in practice this condition is often not met, the values of $\alpha_{i}$ are calculated by the least squares method.

As a result of the first stage of the least squares method, a matrix of incidence of structural types of technological devices to the stages of the technological process is formed, the elements of which are determined as follows:

$e_{i, j}=\left\{\begin{array}{l}1 \\ 0\end{array}\right.$

where:

1 if the apparatus of type $j$ is active in the technological process $i$

0 if the apparatus of type $j$ is not active in the technological process $i$

The second stage of the least squares method consists in choosing the optimal type of instrumental structure of chemical-technological systems for obtaining multi-product products based on the matrix E. Various algorithms for structural optimization of chemical engineering systems are possible. Formally, the structural optimization problem is the listed combinatorial problem, the algorithms for solving which have exponential 
complexity. When listing options for solutions, there is a danger of losing the optimal solution. In the process of solving the problem of structural optimization of multi-product CTS, restrictions are formed on the time of release of assortment products. The procedure for searching for the optimal structure of a chemical system begins with calculating the matrix $G_{m \times m}$ by algorithm $G=E \cdot E^{T}$.

The matrix $G_{m \times m}$ is a matrix whose elements are the number of equipment types that are used in the production of product pairs. The resulting matrix is symmetric about the right diagonal, so it can be converted to rectangular. After determining the possible structural types of CPS by the method of morphological analysis, their permissible structural types are specified, taking into account the completeness of the space of information signs, after which, by the search for non-dominated alternatives, the choice of the optimal structural type of the technological system is performed. Optimization of the type of hardware structure is possible only if it is possible to quantitatively express fuzzy quality criteria.

The stage of choosing the CES hardware structure ends with the formation of a system of time constraints, which are part of the CES structural and functional model. The type of these restrictions depends on the type of the apparatus structure of the chemical-technological system and method of interaction of technological devices.

After determining the admissibility of the CPS classes according to the above algorithm, their priority is determined by the method of finding non-dominated alternatives. A similar procedure is also used to determine the structural-functional models and the efficiency of optimization algorithms.

\section{ALGORITHM APPLICATION. EXAMPLE}

Let's consider an example of the work of the information-logical subsystem of the developed expert system: Working with the program begins with the selection of the required assortment (Table 1).

Table 1 Selection of assortment of paints and varnishes

\begin{tabular}{|c|c|}
\hline Name of the range of paintwork materials & Quantity, tons / year \\
\hline Primer GF-0119 & 500 \\
\hline Varnish PF-283 & 500 \\
\hline Enamel PF-115 & \\
\hline white & 500 \\
\hline cherry & 250 \\
\hline protective & 250 \\
\hline Enamel PF-226 & \\
\hline yellow-brown & 250 \\
\hline red-brown & 250 \\
\hline Enamel ML-12 & 250 \\
\hline white & 250 \\
\hline coffee & 250 \\
\hline blue & \\
\hline
\end{tabular}

The result of the algorithm is a list of types of recommended technological equipment.

Table 2 contains a list of recommended equipment required for the production of selected paints and varnishes. 
Table 2 Selection of equipment for the production of paints and varnishes

\begin{tabular}{|c|c|}
\hline Shop name & Characteristics of technological equipment \\
\hline \multirow{3}{*}{ Reactor department } & Induction heated reactor equipped with agitator and coil \\
\cline { 2 - 2 } & Mixer with cooling jacket with agitator \\
\cline { 2 - 2 } & Shell and tube heat exchanger (reactor condenser) \\
\cline { 2 - 2 } & Shell and tube heat exchanger (mixer condenser) \\
\hline \multirow{2}{*}{ Dispersion department } & Dissolver for continuous mixing \\
\cline { 2 - 2 } & Mixer equipped with agitator \\
\cline { 2 - 2 } & EHP Type Horizontal Bead Mill \\
\cline { 2 - 2 } & Cartridge filter with filtering elements "Cuneau" \\
\cline { 2 - 2 }
\end{tabular}

Subsequently, in the course of the program, the characteristics of individual devices can be changed (if the developers have similar free equipment). At the same time, the expert system checks the suitability of such devices for the production of paints and varnishes using the above algorithms.

\section{CONCLUSION}

Using this expert system, the formulations of the selected assortment of paints and varnishes are determined, and therefore, the types and rates of consumption of raw materials, as well as energy costs. In other words, capital (equipment) and operating (working capital) costs are determined by analyzing the goal via the Internet for the resulting hardware and technological production scheme. All this allows you to determine the effectiveness of the proposed technology and its payback, that is, as a result of the work, you can make a commercial offer for the investor.

\section{REFERENCES}

[1] BOLDYREV, V., MEN'SHIKOV, V., II'DARKHANOVA, F., PUCHKOVA, V., STRAPOLOVA, D. Harmonization of technical demands to paint coatings as a component of competitiveness increase on the international market. In: METAL 2020: 29 $9^{\text {th }}$ International Conference on Metallurgy and Materials. Brno: TANGER, 2020, pp. 649-654.

[2] BOLDYREV, V., MEN'SHIKOV, V., SAVINA, A., BOGATOV, N., ZOTKIN, A., II'DARHANOVA, F., RAZVODOVA, A. General approaches to improving anticorrosion and antifouring coatings. In: METAL 2020: 29 $9^{\text {th }}$ International Conference on Metallurgy and Materials. Brno: TANGER, 2020, pp. 702-705.

[3] BOGOMOLOV, B.B., ZUBAREV, A.M., MESHALKIN, V.P., MEN'SHIKOV, V.V., BOLDYREV, V.S. Intelligent logical information algorithm for choosing energy- and resource-efficient chemical technology. Theoretical Foundation of Chemical Engineering. 2019, vol. 53, no. 5, pp. 709-718.

[4] BOGOSLOVSKII, S.Yu., KUZNETSOV, N.N., BOLDYREV, V.S. Parameter optimization of electrolytic process of obtaining sodium hypochlorite of disinfection of water. Journal of Physics: Conference Series. 2017, vol. 918 , no. 012028.

[5] BOLDYREV, V.S., AVERINA, Yu.M., MENSHIKOV, V.V., KUZNETSOV, S.V., KOLYBANOV, K.Y. Technological and organization engineering of paint processing. Theoretical Foundation of Chemical Engineering. 2020, vol. 54, no. 3, pp. 420-424.

[6] BOGOMOLOV, B.B., MEN'SHIKOV, V.V., BOLDYREV, V.S., AVERINA, Yu.M., ZUBAREV, A.M. Algorithmization of the design calculation of the radiant-convective drying of paint coating. Theoretical Foundation of Chemical Engineering. 2021, vol. 55, no. 1, pp. 70-79.

[7] AVERINA, Yu.M., KALYAKINA, G.E., MEN'SHIKOV, V.V. et al. Neutralisation process design for electroplating industry wastewater containing chromium and cyanides. Herald of the Bauman Moscow State Technical University, Series Natural Sciences. 2019, no. 3, pp. 70-80. 